\title{
Challenges, burden and emotional impact on Portuguese athletes during COVID-19 pandemic
}

\section{Retos e impacto emocional de la pandemia en los deportistas portugueses durante la pandemia de COVID-19 Os desafios e o impacto emocional nos atletas portugueses durante a pandemia COVID-19}

\author{
Oliveira, S. ${ }^{1}$, Cunha, M. ${ }^{2}$, Rosado, A. ${ }^{3}, \&$ Ferreira, C. ${ }^{1}$ \\ ${ }^{1}$ CINEICC - Center for Research in Neuropsychology and Cognitive Behavioural Intervention, Faculty \\ of Psychology and Educational Sciences, University of Coimbra (Portugal); ${ }^{2}$ Center for Research in \\ Neuropsychology and Cognitive Behavioural Intervention; ${ }^{3}$ FMH - Faculty of Human Kinetics, \\ University of Lisbon (Portugal)
}

\begin{abstract}
This study aimed to explore how contextual variables associated with the period of confinement during pandemic can differentiate symptoms of anxiety, depression, and stress. It also intended to understand the concerns that were experienced by athletes when resuming their sport practice and how these could be associated with psychopathological indicators. The sample comprised 265 athletes who completed self-reported questionnaires. Results demonstrated that there were differences in psychopathological indicators in terms of hours of training per week, and the type of contact that athletes have with their coach. Athletes reported concerns regarding the resumption of sport practice, and that were associated with anxiety, depression, and stress symptoms. This study may contribute in warning the sports community about the impact of contextual variables-related to critical moments of this pandemic. Sports communities should encourage the preservation of the athlete's physical activities, as well as supporting coaches in continuing to guide athlete's training.
\end{abstract}

Keywords: athletes; concerns; COVID-19 pandemic; mental health

\section{RESUMEN}

Este estudio tuvo como objetivo explorar como las variables contextuales asociadas con el período de confinamiento de la pandemia pueden discriminar los síntomas de ansiedad, depresión y estrés. También se pretendió comprender las preocupaciones al retomar práctica deportiva y como estas podrían estar asociadas con indicadores psicopatológicos. La muestra incluyó 265 deportistas que completaron cuestionarios de autorespuesta. Los resultados demostraron que existen diferencias en los indicadores psicopatológicos en las horas de entrenamiento y el tipo de contacto que los deportistas tienen con su entrenador. Los atletas reportaron preocupaciones con respecto a la reanudación de la práctica deportiva después del período de confinamiento social, que se asociaron con síntomas de ansiedad, depresión y estrés. Este estudio puede contribuir a advertir a la comunidad deportiva sobre el impacto de las variables contextuales relacionadas con esta pandemia. Las comunidades deportivas deben fomentar la 


\section{Challenges and emotional impact on Portuguese athletes during COVID-19 pandemic}

preservación de las actividades físicas, y apoyar a los entrenadores para que sigan guiando el entrenamiento de sus atletas.

Palabras clave: deportistas; preocupaciones; pandemia COVID-19; salud mental.

\section{RESUMO}

O objetivo deste estudo foi explorar como é que variáveis contextuais associadas ao período de confinamento resultante da pandemia COVID-19 podem discriminar sintomas de ansiedade, depressão e stress em atletas. Adicionalmente, pretendeu-se explorar as preocupações mais experienciadas pelos atletas aquando da retoma da sua prática desportiva, e como é que estas se associam a indicadores psicopatológicos. Participaram neste estudo 265 atletas que completaram medidas de autorrelato. Os resultados demonstraram que existem diferenças nos indicadores psicopatológicos em termos de horas de treino por semana e do tipo de contacto que os atletas mantiveram com o treinador. Este estudo demonstrou que os atletas reportam preocupações relativamente à retoma da sua prática após o período de confinamento, e que estas preocupações foram associadas a sintomas de ansiedade, depressão e stress. Este estudo tem importantes implicações práticas, alertando a comunidade desportiva para o impacto de variáveis contextuais associadas à pandemia. As comunidades desportivas devem encorajar a preservação das rotinas dos atletas, e incentivar os treinadores a continuarem a orientar o treino dos seus atletas.

Palavras-chave: atletas; preocupações; pandemia COVID-19; saúde mental.

\section{INTRODUCCIÓN}

The Coronavirus disease of 2019 (COVID-19), which originated in the city of Wuhan, Central China, is an infectious disease that spread quickly around the world (WHO, 2020a). COVID-19 is caused by a novel coronavirus, named severe acute respiratory syndrome coronavirus 2 (SARS-CoV-2; WHO, 2020a). At present, the newly identified SARS-CoV-2 has caused a large number of deaths with millions of confirmed cases worldwide, posing a serious threat to public health (WHO, 2020a). On March 11, 2020, the World Health Organization (WHO) declared coronavirus (COVID-19) a pandemic, in other words, a global disease outbreak that threatens the whole planet (WHO, 2020a).

The COVID-19 pandemic outbreak has affected the society in a sudden and dramatic manner with an unprecedented impact on the health and daily life of all citizens (WHO, 2020b). The governments of the majority of countries have enforced border shutdowns, travel restrictions and quarantine (WHO, 2020c). In fact, the COVID-19 outbreak had a major impact on all types of social contexts, and sport is no exception (WHO, 2020d). Some authors have indicated that as athletes are younger and have less comorbidities (e.g., hypertension and obesity) in comparison to the general population, they are at a lower risk of severe disease or death (Toresdahl \& Asif, 2020; Wu \& McGoogan, 2020). However, preventing the transmission of COVID-19 is necessary to protect those at high risk of death and to slow the pandemic down to guarantee that health care systems do not exceed their capacity (Toresdahl \& Asif, 2020). Firstly, it is necessary to prevent athletes from spreading the virus, therefore reducing the risk of contamination to the most vulnerable population (Wu \& McGoogan, 2020). On the other hand, asymptomatic people are also those who have less control of themselves, since they do not know that they are carrying the virus and spreading it to those who they contact with (Shi et al., 2020). Thus, in case of contamination, athletes, who are mainly healthy, are more likely to only present mild symptoms or are even be asymptomatic, which may increase the risk of contamination to other people (Toresdahl \& Asif, 2020; Wu \& McGoogan, 2020). For these reasons, all major sports leagues and tournaments have been suspended or cancelled since early March 2020 (e.g., UN, 2020). Therefore, to safeguard the health of athletes and others involved, most major sporting events independent of their level of competition (international, regional, or national) have been cancelled or postponed - from marathons to football tournaments, athletics championships to basketball games, handball to ice hockey, rugby, cricket, sailing, skiing, weightlifting to wrestling and more (UN, 2020). In fact, the Olympics and the Paralympics of 2020 were postponed, and will be held in 2021 (UN, 2020).

Suspending seasons and cancelling competitions can cause significant grief, stress, anxiety, frustration, and 


\section{Oliveira et al.}

sadness for an athlete (Toresdahl \& Asif, 2020). Between March 22nd and April 14th, the International Federation of Professional Footballers (FIFPRO, 2020) and affiliated national player associations surveyed 1.602 professional footballers in countries that had implemented measures to contain the spread of the coronavirus (such as mass home-confinement). Results demonstrated that $22 \%$ of female players and $13 \%$ of male players reported symptoms consistent with a diagnosis of depression. Eighteen percent of the women and $16 \%$ of the men reported symptoms consistent with a diagnosis of generalized anxiety (FIFPRO, 2020). In fact, it appears that the coronavirus is not only a risk to physical health, but it also has an impact on the mental health of individuals (FIFPRO, 2020; Hamouche et al., 2020; Hull et al., 2020).

The psychological impact of COVID-19 on a competitive athlete is potentiated by the removal of his or her social support network and normal training routine, which for some is a critical component of managing depression or anxiety (Toresdahl \& Asif, 2020). Sport can contribute to people's health, socialization, education and a general sense of wellbeing. Therefore, the COVID-19 pandemic, in addition to its negative short and mid-term health impact (including inactivity, mental health risks related to loneliness and anxiety), will also have longterm consequences on people's daily lives, health, and generally on societies and many service sectors, such as sport (European Platform for Sport Innovation, 2020). Indeed, like most citizens, athletes are also facing anxiety, fear and frustration in the face of this new conjuncture, and these particular questions and doubts, arising from the isolation, may have profound impacts on sports performance (Order of Portuguese Psychologists, 2020). In particular, for athletes who aim to participate in competitions (e.g., championships, Olympic Games, tournaments), their suspension or postponement means the rescheduling of all the work that the athletes have focused on for months and / or years, which leads to negative affects, such as experiences of stress, anxiety, and depression (Hull et al., 2020; Mehrsafar et al., 2020). In this sense, some guidelines have been published by professionals of sports medicine to help athletes deal with this type of confinement, such as the maintenance of the routines whenever possible, physical exercise, and maintaining contact with coaches and teammates by phone or video chat. Indeed, the maintenance of a training routine is an important component to protect an athlete's mental health, particularly in reducing the risk of anxiety and depression (Hull et al., 2020; Mehrsafar et al., 2020; WHO, 2020c). For example, the World Health Organization recommends that all adults should do at least 150 minutes of moderateintensity physical activity throughout the week, or at least 75 minutes of vigorous-intensity physical activity throughout the week (WHO, 2020e). Additionally, videos from many well-known athletes showed how they tried to overcome these challenges, continuing with alternative training, adapting wherever possible during the pandemic (Mehrsafar et al., 2020). However, although there are primary guidelines to help athletes deal with this pandemic, there are no studies that explore the effect of these guidelines on athletes' mental health.

Also, many athletes have been confronted with questions associated with the impact that this new condition of isolation will have on their sporting performance (e.g., "What implications will this interruption have on my performance?"; Psychology \& Performance Practice Group, 2020). Taking into account that the COVID-19 pandemic has affected athletes' sports routines and trigged concerns associated with the impact of this new condition on sports performance, it is important to explore how contextual variables related to the period of isolation have an impact on athletes' mental health. In fact, it would be important to understand the major concerns of athletes regarding the resumption of all aspects related to their sporting activity and how these concerns may be associated with indicators of mental health.

The present research aimed to: 1) explore how certain contextual variables associated with the period of confinement that has resulted from the COVID-19 pandemic (e.g., being in quarantine; belonging to a group that is more at risk of severe COVID-19 disease; not keeping in contact with teammates and with coaches; having workouts prepared by coaches and having access to their feedback) can differentiate symptoms of anxiety, depression, and stress; 2) understand which concerns are most experienced by athletes regarding the resumption of sports practice and how these concerns are associated with symptoms of anxiety, depression, and stress.

\section{MATERIAL AND METHODS}




\section{Challenges and emotional impact on Portuguese athletes during COVID-19 pandemic}

\section{Participants}

The sample of the present study comprised 265 Portuguese adult athletes of both sexes (133 males and 132 females) with a mean age of $24.12(S D=6.47)$. All of the athletes actively compete in sports: $54 \%$ of the athletes indicated compete in individual sports (namely, athletics, cycling, judo, karate, boxing, muay thai, figure skating, speed skating, surf, taekwondo, tennis, and triathlon), and $46 \%$ compete in team sports (namely, handball, basketball, canoeing, korfball, football, beach soccer, futsal, roller hockey, water polo, rowing, roller derby, rugby, and volleyball). Participants had on average played their sport for 11.53 years $(S D=6.25)$ and had been competing at district $(n=36,13.6 \%)$, regional $(n=18 ; 6.8 \%)$, national $(n=149 ; 56.2 \%)$, and international $(n=62$; $23.4 \%$ ) levels. None of the participants had been infected by COVID-19.

\section{Instruments}

Sociodemographic characteristics, characteristics associated to sport practice before and during the COVID-19 pandemic, and concerns regarding the resumption of sports after the period of social confinement were obtained through a data sheet specifically developed by the researchers for this study using open and closed-ended questions. To assess anxious, depressive, and stress related symptoms empirically validated self-reported questionnaires were administered.

\section{Sociodemographic characteristics}

Participants provided a variety of demographic information including: age, gender, sport practiced, years of competitive experience, and level of sport competition.

Characteristics related to the situation of social confinement and characteristics associated to sport practice during the COVID-19 pandemic

With regard to characteristics related to the situation of social confinement and characteristics associated to sport practice during the COVID-19 pandemic, the athletes were asked according to the questions presented in table 1. These questions were divided in three categories: level of confinement; level of risk of severe COVID-19 disease; nature of sports setting during pandemic.
Concerns regarding the resumption of sports after the period of social confinement

Concerns regarding the resumption of sports after the period of social confinement were assessed through a data sheet specifically developed by the researchers for this project. The questions were drawn up on the basis of the opinion articles that have been published and on information regarding the impact of the COVID-19 pandemic on sport. Responses were completed on a 5-point rating scale which ranges from " 0 = Nothing applies to me" to " $4=$ Applies entirely to me" to report respondents' level of appliance of each concern (see table 2).

\section{Anxiety and depression symptoms}

The 4-item Patient Health Questionnaire-4 (PHQ-4; Kroenke, et al., 2009) was used to assess the presence of anxious and depressive symptoms. PHQ-4 is an ultra-brief self-report questionnaire that consists of a 2-item depression scale and a 2-item anxiety scale. This 4 item inventory rated on a 4 point Likert-type scale ( $0=$ "not at all" to $3=$ "nearly every day") assesses the frequency of each symptom during the last two weeks. On each subscale, a score equal to or higher than 3 is considered clinically significant. Total PHQ-4 scores equal to or higher than 6 indicate a warning sign of depression or anxiety disorder. PHQ4 presented good reliability, with alpha values of .82 and .81 for anxiety and depression subscales, respectively. In the current study, subscales of PHQ-4 were used and presented alpha values of .87 and .73 for anxiety and depression subscales, respectively.

\section{Perceived Stress}

The Perceived Stress Scale (PSS; Cohen \& Williamson, 1988; Trigo et al., 2010) is a stress assessment instrument. This measure allows the understanding of how different situations affect an individual's feelings and their perceived stress. The questions in this scale, rated on a 5 point Likert-type scale $(0=$ "never" to $4=$ "very often"), questioned participants about feelings and thoughts during the last month. PSS showed good reliability, with alpha values of .78 and .87 for original and Portuguese version, respectively. In this study, PSS presented an alpha value of .83 .

Procedures 


\section{Oliveira et al.}

This study is a part of a wider research project about the impact of different factors and processes of emotional regulation on the quality of life and mental health of athletes, conducted at the Center for Research in Neuropsychology and Cognitive Behavioural Intervention. The procedures respected all ethical and deontological requirements inherent to scientific research and the study was approved by the Ethical Board of the Faculty of Psychology and Education Sciences of the University of Coimbra on $1^{\text {st }}$ April 2020.

This study was advertised on social network sites and the sample was collected between April 2020 and May2020 (period in which a state of emergency was decreed in Portugal). In this sense, an invitation to participate in this study was electronically sent through popular social networks (Facebook) to potential participants. The online advertisement included an informative text that clarified the aims and procedures of the investigation, the voluntary and confidential character of their participation and the inclusion criteria of participants' selection. The online advertisement also included an Internet link to the online platform (GoogleForms) with the informed consent and protocol. Thus, participants who accepted to participate in the study $(N=271)$ gave their informed consent and completed the online survey. Considering the aims of the present study, the database was cleaned to exclude: (i) participants who completed the survey but were not athletes; (ii) participants younger than 18 years. This process resulted in a final sample of 265 athletes. There were no missing data because the platform only allows the submission of the questionnaires when all questions have been answered.

\section{Data analysis}

All data analyses were conducted using SPSS Statistics software, version 22.0 (IBM, Armonk, NY).

The normality of the distribution of the study variables was analyzed by Kolmogorov-Smirnov test. To analyse the characteristics of the sample, descriptive statistical analyses were performed. Comparison tests were performed to identify differences among contextual variables related to the period of isolation resulting from the COVID-19 pandemic in anxiety, depression, and stress symptoms. Kruskal-Wallis tests, post hoc Mann-Whitney U-tests with Bonferroni correction, and student's t tests were used.
Descriptive statistics (frequencies, means and standard deviations) were conducted to assess the concerns that were more experienced by athletes regarding the resumption of sports practice after the confinement. Spearman correlations were estimated to analyse the relationship between each concern regarding the resumption of sports after the period of social confinement and symptoms of anxiety, depression, and stress. The analysis of the magnitudes of the results followed the recommendations of Cohen and colleagues (Cohen et al., 2003).

\section{RESULTS}

\section{Preliminary analysis}

The normality of the distribution of the study variables was analyzed by Kolmogorov-Smirnov test. Results revealed that data presented a non-normal distribution $\left(\mathrm{D}_{(265)}=.27, p<.001 ; \mathrm{D}_{(265)}=.23, p<.001 ; \mathrm{D}_{(265)}\right.$ $=.08, p<.001)$ for anxiety, depressive and stress symptoms, respectively.

\section{Sample's characterization in psychopathological indicators}

Regarding psychopathological indicators, in this sample means of $2.02(S D=1.50), 1.97(1.55)$, and 17.20 (7.22) were found in anxiety, depression, and stress scales, respectively. Also, 62 participants (23.4\%) and 69 participants (26\%) presented clinically significant levels of anxiety and depressive symptoms, respectively.

Concerns experienced by athletes regarding the resumption of sports practice after the confinement period

Among the eleven types of concerns regarding the resumption of sports practice after the period of social confinement, athletes reported experiencing the following concerns more frequently: worries about possible new challenges when resuming sports; concerns about how the current changes in their routines (e.g., hours of sleep, food) would influence their future sports performance; worries about losing talent or technical skills; and worries about their physical condition (see table 1).

Table 1. Means values $(M, S D)$ and frequencies $(N, \%)$ of the athletes' concerns regarding the resumption of sports practice after the social confinement 


\section{Challenges and emotional impact on Portuguese athletes during COVID-19 pandemic}

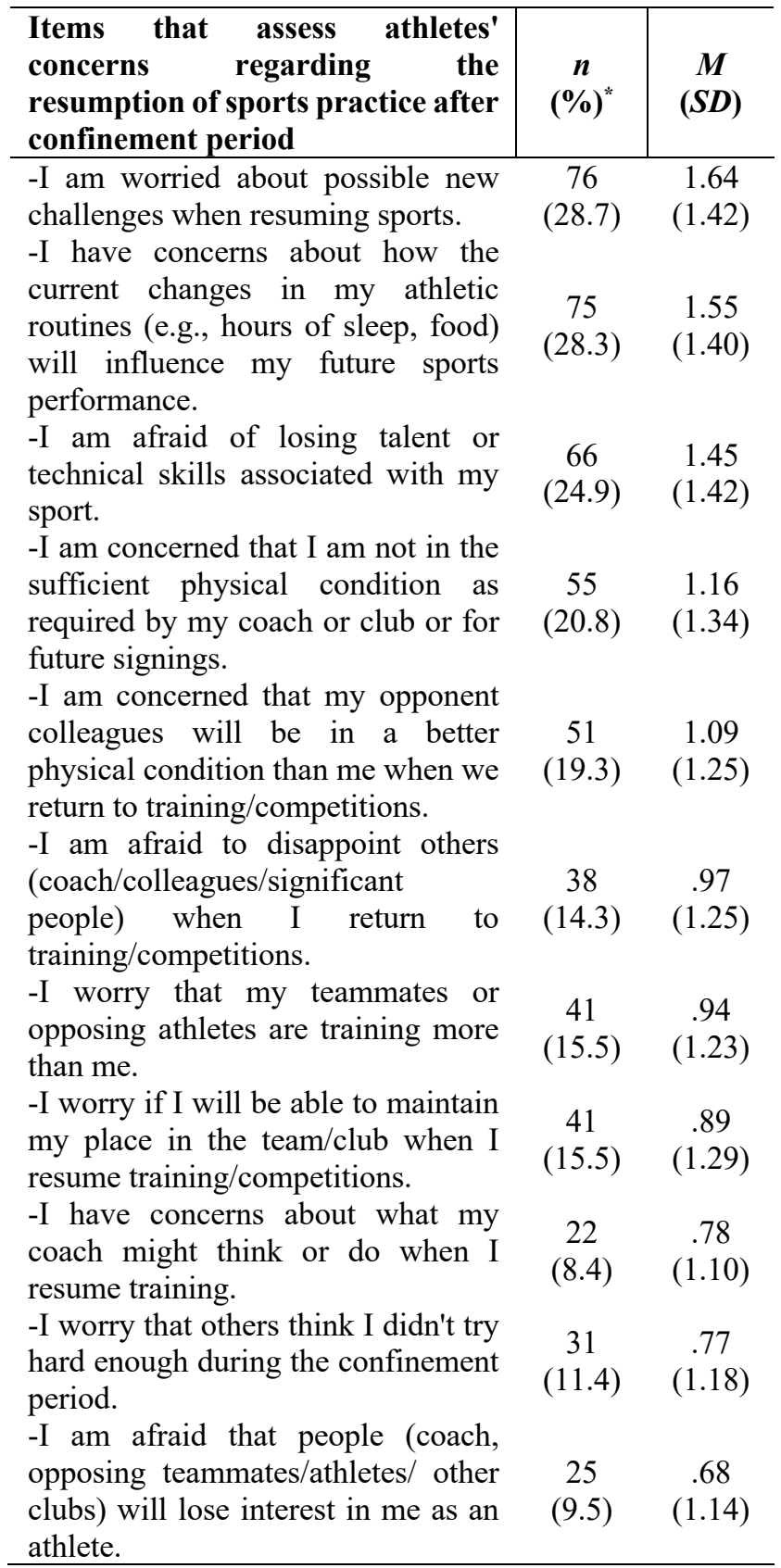

How do contextual variables associated with the period of confinement that has resulted from the Covid-19 pandemic, differentiate symptoms of anxiety, depression, and stress in athletes?

Results demonstrated that there were no differences in anxious, depressive, and stress symptoms regarding a quarantine situation. However, there were statistically significant differences in symptoms of depression and stress in athletes who belonged to a group at risk of severe COVID-19 disease in comparison to those who did not. Athletes who belonged to this risk group presented higher levels of depression and stress related symptoms.

Taking into account that only 6 athletes stopped doing physical exercise during the COVID-19 pandemic, they were excluded from the analysis in relation to the remaining contextual variables associated with sports practice during the outbreak. Regarding characteristics associated to sport practice during the COVID-19 pandemic (e.g., hours of training per week), statistically significant differences between athletes who trained less then 2.30 hours per week and athletes who trained at least 2.30 hours per week were presented in relation to anxious, depressive, and stress symptoms.

Athletes who trained less 2.30 hours per week presented significantly higher levels of anxiety, depression, and stress. However, in terms of symptoms of anxiety, depression, and stress, there were no differences between athletes who kept in contact with their teammates and with their coaches and athletes who did.

Also, in relation to depressive symptoms, there were statistically significant differences between athletes whose coaches prepared workouts and athletes whose coaches did not (athletes whose coaches prepared workouts presented lower levels of depression). This was not the case for anxious and stress symptoms. Finally, with regard to depressive and stress symptoms, there are differences between athletes whose coaches gave them feedback of their workouts and athletes whose coaches did not. However, this was not the case for anxiety related symptoms. In fact, athletes whose coaches gave them feedback of their workouts presented lower levels of depression and stress symptoms (see Table 2). 


\section{Oliveira et al.}

Table 2. Comparison of mean values (M, SD) of symptoms of Anxiety, Depression, and Stress in terms of contextual issues associated with the COVID-19 pandemic

\begin{tabular}{|c|c|c|c|c|c|c|}
\hline \multirow[b]{2}{*}{ Contextual issues } & \multicolumn{2}{|c|}{ Anxiety } & \multicolumn{2}{|c|}{ Depression } & \multicolumn{2}{|c|}{ Stress } \\
\hline & $M(S D)$ & $K-W / U\left(n^{2}\right) t(d)$ & $M(S D)$ & $K-W / U\left(n^{2}\right) t(d)$ & $M(S D)$ & $K-W / U(n 2) t(d)$ \\
\hline \multicolumn{7}{|l|}{ Level of quarantine } \\
\hline \multicolumn{7}{|l|}{ 1. Are you in isolation or quarantined? } \\
\hline $\begin{array}{l}\text { Yes, I am in quarantine - I was in contact with a } \\
\text { patient infected with the virus }(n=6)\end{array}$ & $2.17(1.33)$ & \multirow{3}{*}{$1.149(.003)$} & $2.67(1.97)$ & & $19.00(8.79)$ & \multirow{3}{*}{$1.353(.002)$} \\
\hline $\begin{array}{l}\text { No, I am at home, but without isolation/quarantine } \\
\text { measures - only with essential outings }(n=236)\end{array}$ & $2.04(1.51)$ & & $1.97(1.55)$ & $1.182(.003)$ & $17.28(7.27)$ & \\
\hline No, I keep leaving the house $(n=23)$ & $1.83(1.50)$ & & $1.78(1.54)$ & & $15.83(6.26)$ & \\
\hline \multicolumn{7}{|l|}{ Level of risk of severe COVID-19 disease } \\
\hline \multicolumn{7}{|l|}{$\begin{array}{l}\text { 2. Do you belong to any of the risk groups for severe } \\
\text { COVID-19 disease? }\end{array}$} \\
\hline Yes $(n=21)$ & $2.48(1.47)$ & \multirow[t]{2}{*}{$2094.00(.007)$} & $3.05(1.99)$ & \multirow{2}{*}{$\mathbf{1 6 8 0 . 0 0}^{* *}(.026)$} & $20.29(7.16)$ & \multirow[t]{2}{*}{$1865.00 *(.016)$} \\
\hline No $(n=244)$ & $1.98(1.50)$ & & $1.88(1.48)$ & & $16.93(7.17)$ & \\
\hline \multicolumn{7}{|l|}{ Nature of sports setting } \\
\hline \multicolumn{7}{|l|}{$\begin{array}{l}\text { 3. Do you train at least } 2.30 \text { hours per week during the } \\
\text { period of social confinement? }\end{array}$} \\
\hline Yes $(n=247)$ & $1.93(1.45)$ & \multirow{2}{*}{$\mathbf{5 2 7 . 0 0}^{* * * *}(.071)$} & $1.85(1.44)$ & \multirow{2}{*}{$\mathbf{6 6 6 . 0 0}^{* *}(.081)$} & $16.68(6.82)$ & \multirow[t]{2}{*}{$626.50 * *(.063)$} \\
\hline No $(n=12)$ & $3.83(1.59)$ & & $3.92(2.07)$ & & $25.17(9.08)$ & \\
\hline \multicolumn{7}{|l|}{$\begin{array}{l}\text { 4. Do you keep in contact with your } \\
\text { teammates/colleagues? }\end{array}$} \\
\hline Yes $(n=180)$ & $2.11(1.53)$ & \multirow{2}{*}{$-1.546(.210)$} & $2.04(1.57)$ & \multirow{2}{*}{$-1.627(.220)$} & $17.27(6.88)$ & \multirow[t]{2}{*}{$-.657(.087)$} \\
\hline No $(n=79)$ & $1.80(1.42)$ & & $1.71(1.43)$ & & $16.63(7.74)$ & \\
\hline \multicolumn{7}{|l|}{ 5. Do you keep in contact with your coach? } \\
\hline Yes $(n=181)$ & $2.09(1.56)$ & \multirow{2}{*}{$-1.278(.178)$} & $1.99(1.55)$ & \multirow{2}{*}{$-.837(.112)$} & $17.21(7.15)$ & \multirow[b]{2}{*}{$-.487(.066)$} \\
\hline No $(n=78)$ & $1.83(1.36)$ & & $1.82(1.49)$ & & $16.74(7.15)$ & \\
\hline \multicolumn{7}{|l|}{ 6. Are the training sessions prepared by your coach? } \\
\hline Yes $(n=147)$ & $1.90(1.37)$ & 1.321 & $1.72(1.29)$ & \multirow[t]{2}{*}{$\mathbf{2 . 5 8 2}^{*}(.330)$} & $16.51(6.58)$ & \multirow{2}{*}{$1.457(.181)$} \\
\hline No $(n=112)$ & $2.16(1.67)$ & $(.164)$ & $2.23(1.77)$ & & $1781(7.78)$ & \\
\hline \multicolumn{7}{|l|}{ 7. Does your coach give feedback on your workouts? } \\
\hline Yes $(n=152)$ & $1.91(1.42)$ & $1.257(.164)$ & $1.72(1.36)$ & $2.661^{* * *}(.343)$ & $16.34(6.56)$ & \\
\hline No $(n=107)$ & $2.16(1.62)$ & & $2.25(1.71)$ & & $18.11(7.81)$ & $1.975^{*}(.245)$ \\
\hline
\end{tabular}

Note. Effect sizes were assessed with $\eta^{2}$ (Kruskal Wallis and Mann-whitney $\mathrm{U}$ testes) and with $d$ Cohen (student's $\mathrm{t}$ tests): small effect sizes ( $\eta 2 \geq .02 ; d \geq .20$ ); medium effect sizes $\left(\eta^{2} \geq .13 ; d \geq .50\right)$; large effect sizes $(\eta 2 \geq .26 ; d \geq .80)$ (Cohen, 1992).

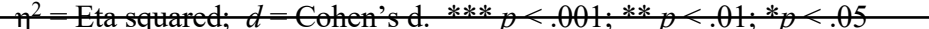




\section{Challenges and emotional impact on Portuguese athletes during COVID-19 pandemic}

Correlations between athletes' concerns regarding the resumption of sports practice after the confinement period and anxiety, depression, and stress

All athletes' concerns regarding the resumption of sports practice after the period of social confinement showed positive and significant correlations with anxiety, depression and stress related symptoms (with weak and moderate magnitudes; see table 3).

Table 3. Correlations between athletes' concerns regarding the resumption of sports practice after the confinement period and anxiety, depression, and stress.

\begin{tabular}{|c|c|c|c|}
\hline $\begin{array}{l}\text { Items that assess athletes' concerns regarding } \\
\text { the resumption of sports practice after the } \\
\text { confinement period }\end{array}$ & Anxiety & Depression & Stress \\
\hline $\begin{array}{l}\text {-I worry about possible new challenges when } \\
\text { resuming sports. }\end{array}$ & $.22^{* * *}$ & $.22^{* * *}$ & $.23^{* * *}$ \\
\hline $\begin{array}{l}\text { I have concerns about how the current changes in } \\
\text { my athletic routines (e.g., hours of sleep, food) } \\
\text { will influence my future sports performance. }\end{array}$ & $.31^{* * *}$ & $.26^{* * *}$ & $.34^{* * *}$ \\
\hline $\begin{array}{l}\text {-I am afraid of losing talent or technical skills } \\
\text { associated with my sport. }\end{array}$ & $.36^{* * *}$ & $.35^{* * *}$ & $.38^{* * *}$ \\
\hline $\begin{array}{l}\text {-I am concerned that I am not in the sufficient } \\
\text { physical condition as required by my coach / club } \\
\text { or for future signings. }\end{array}$ & $.32^{* * *}$ & $.23^{* * *}$ & $.33^{* * *}$ \\
\hline $\begin{array}{l}\text {-I am concerned that my opponent colleagues or } \\
\text { athletes will be in a better physical condition than } \\
\text { me when we return to training / competitions. }\end{array}$ & $.21^{* *}$ & $.17^{* *}$ & $.22^{* *}$ \\
\hline $\begin{array}{l}\text {-I am afraid to disappoint others (coach / } \\
\text { colleagues / significant people) when I return to } \\
\text { training / competitions. }\end{array}$ & $.30^{* * *}$ & $.29^{* * *}$ & $.30^{* * * *}$ \\
\hline $\begin{array}{l}\text {-I worry that my teammates or opposing athletes } \\
\text { are training more than me. }\end{array}$ & $.25^{* * *}$ & $.19^{* *}$ & $.24^{* * *}$ \\
\hline $\begin{array}{l}\text {-I worry if I will be able to maintain my place in } \\
\text { the team / club when I resume training / } \\
\text { competitions. }\end{array}$ & $.19^{* *}$ & $.13^{*}$ & $.19^{* *}$ \\
\hline $\begin{array}{l}\text {-I have concerns about what my coach might think } \\
\text { or do when I resume training. }\end{array}$ & $.25^{* * *}$ & $.20^{* *}$ & $.25^{* * *}$ \\
\hline $\begin{array}{l}\text {-I worry that others think I didn't try hard enough } \\
\text { during the confinement period. }\end{array}$ & $.31^{* * *}$ & $.24^{* * *}$ & $.30^{* * *}$ \\
\hline $\begin{array}{l}\text {-I am afraid that people (coach, opposing } \\
\text { teammates / athletes, other clubs) will lose interest } \\
\text { in me as an athlete. }\end{array}$ & $.29^{* * *}$ & $.26^{* * *}$ & $.29^{* * *}$ \\
\hline
\end{tabular}

Note: ${ }^{* * *} p<.001 ; * * p<.01 ; * p<.05$

\section{DISCUSSION}

The COVID-19 pandemic has altered the life of all citizens and athletes are no exception (Hull et al., 2020). The changes associated with the current pandemic have presented athletes with multiple challenges (Hull et al., 2020). Observing the recommendations of health authorities, several athletic events have been postponed or cancelled in an attempt to limit the spread of the virus by attending crowds (WHO, 2020c). These cancellations and wide-spread mandates for social distancing are negatively affecting athletes who are unable to continue regular training (WHO, 2020c). In fact, the applied quarantine 


\section{Oliveira et al.}

regulations and subsequent isolation have affected many athletes' ability to practice (Mehrsafar et al., 2020) and may have an impact of their mental health. In this sense, the present research is an exploratory study that aims to: explore how certain contextual variables associated with the period of confinement that has resulted from the COVID-19 pandemic, (e.g., keeping or not keeping in contact with teammates and with coaches; having workouts prepared by coaches or not, etc.) differentiate symptoms of anxiety, depression, and stress. Also, in face of the multiple challenges resulting from the COVID-19 pandemic, this study intended to understand which concerns are most experienced by athletes when resuming their sports practice and how these concerns are associated with anxiety, depression, and stress related symptoms.

In this sample, $23.4 \%$ and $26 \%$ of participants revealed clinically significant levels of anxiety and depression, respectively. The results of the current study demonstrated that there are no differences in terms of anxiety, depression, and stress symptoms regarding quarantine. However, results showed that there were differences in terms of stress symptoms between athletes who belonged to a group at risk of severe COVID-19 disease in comparison to those who did not. These results are in line to information provided from the Centers for Disease Control and Prevention (2020) that highlighted that the outbreak of coronavirus disease 2019 may be stressful for people, and that every person reacts differently to stressful situations. Centers for Disease Control and Prevention highlighted that, how people respond to the outbreak can depend on their background, and the community they live in. However, Centers for Disease Control and Prevention (2020) have warned that people with chronic diseases who are at higher risk of severe illness from COVID-19 may be more susceptible to stress.

Therefore, the current study supports the previous information of Centers for Disease Control and Prevention, demonstrating that there are differences in terms of stress symptoms between athletes who belong to a group at risk of severe COVID-19 disease in comparison to those who do not. Also, our results extended information, showing that there are not only differences in terms of stress but also in terms of depressive symptoms. In fact, people who belong to a risk group for severe COVID-19 disease could experience higher levels of entrapment and defeat, which could explain higher levels of depressive symptoms. However, in our sample, none of the athletes were infected with the COVID-19 disease and the majority reported that they continued to exercise during the period of social isolation. With regard to characteristics associated to sport practice during the COVID-19 pandemic, our results demonstrated that athletes who trained less than 2.30 hours per week presented significantly higher levels of anxiety, depression, and stress in comparison to athletes who trained at least 2.30 hours per week.

These results seem to be in accordance with recommendations of WHO that highlighted that all adults should do at least 150 minutes of moderateintensity physical activity throughout the week (WHO, 2020e). Also, these results are in accordance with previous literature, which demonstrated that depressive symptoms were associated with less time spent on total physical activity, higher levels of sedentary behavior and a lower likelihood to meet the physical activity levels recommended by guidelines (Belvederi-Murri et al., 2018).

Additionally, our results showed that there were no differences in anxiety, depression, and stress levels in athletes who kept in contact with coaches and with teammates in comparison to those who did not, contrary to what was expected, since the Portuguese Psychologists Association highlighted that it is important to maintain contact with coaches and teammates by phone or video chat, among others (Portuguese Psychologists Association, 2020). However, the current study suggested that it is important that coaches prepare and give feedback on athletes' workouts, since athletes whose coaches prepared and gave feedback of their training presented lower levels of psychopathological indicators. In fact, these results are in line with some authors that highlighted that without constructive guidance and support, athletes finding themselves unforeseeably inactive, or without direction, tend to suffer from substantive psychological stress and potential mental ill health (e.g., Oliveira et al., 2021a, 2021b; Schinke et al., 2020).

Our results are in accordance with some authors who have highlighted that periods of inactivity, isolation from athletic teams, distance from the athletic community, less qualified interactions with athletic coaches, and lack of social support have been demonstrated to cause emotional distress and 


\section{Challenges and emotional impact on Portuguese athletes during COVID-19 pandemic}

psychological disorders in athletes (Reardon et al., 2019).

In addition, this study intended to understand which concerns are most experienced by athletes regarding the resumption of sports practice and how these concerns are associated with anxiety, depression, and stress related symptoms. This study demonstrated that among the selected types of concerns regarding the resumption of sports practice after the period of social confinement, athletes reported experiencing the following concerns more frequently: worries about possible new challenges when resuming sports; concerns about how the current changes in their routines would influence their future sports performance; worries about losing talent or technical skills; and worries about their physical condition. To our knowledge, there are no studies about the main worries that athletes may have regarding the resumption of sports practice after a period of social confinement.

However, some authors highlighted that the cancellation of leagues and competitions that are a source of income will greatly affect many teams around the globe (Mehrsafar et al., 2020; Toresdahl \& Asif, 2020). While teams and coaches might try to find ways to save elite athletes first, lower-level athletes are prone to more challenges under these conditions (Mehrsafar et al., 2020; Toresdahl \& Asif, 2020). Since the changes associated with the current pandemic (e.g., cancellation of leagues and competitions; uncertainty about the sports calendar) have presented athletes with multiple challenges (new ways to training; alteration of athletes' routines), athletes seems to be concerned with new challenges that may occur when they resume sports practice and what impact these challenges may have on their life as an athlete (e.g., alteration of routines on sport performance). Also, literature has highlighted that success in sport events depends upon the optimum combination of psychological factors, tactical and technical skills, and physical condition (e.g., Cureton, 1956; Liew et al., 2019).

Our results demonstrated that among the concerns most experienced by athletes were concerns with the possibility of losing talent or skills associated with their sport ("I am afraid of losing talent or technical skills associated with my sport") and with physical condition ("I am concerned that I am not in the sufficient physical condition as required by my coach/club or for future signings"; "I am concerned that my opponent colleagues or athletes will be in better physical condition than me when we return to training/ competitions"). In addition and in general, these results showed that the concerns most experienced by athletes focus on the challenges they need to face at an individual level (e.g., "I am afraid of losing talent or technical skills associated with my sport"). Their concerns associated with others ("I am afraid that people - coach, opposing teammates/athletes/ other clubs- will lose interest in me as an athlete") were less experienced by athletes.

Also, all the concerns specifically designed for the current study were associated positively with higher levels of anxiety, depression, and stress. These results seem to suggest that the changes associated with the COVID-19 pandemic have presented athletes with multiple challenges and these challenges trigger several concerns in athletes regarding the resumption of sports practice after the period of social confinement that, in turn, are associated with psychopathological symptoms. Therefore, this study seems to suggest that the COVID-19 pandemic and its subsequent effects could have a negative impact on athletes' mental health.

However, this study warns of the role that some variables can play in a pandemic, specifically in psychopathological indicators. For example, this study showed the importance of physical exercise and the coach's degree of involvement with athletes in difficult times such as the current one. In this sense, it seems to be important that, in critical situations or in future pandemics, sports communities encourage, the preservation of athletes' physical activities whenever possible, as well as supporting coaches to continue to guide athletes' training.

This study seems to suggest that it is not enough that athletes continue to maintain contact with coaches, but that the latter should guide the athletes during these critical periods. In addition, the current study also has practical implications for psychologists. It would be important to address the concerns of athletes regarding the resumption of their sport and to encourage coping strategies to deal with new challenges.

This study should not be considered without taking in account some limitations. First, these findings are based on cross-sectional data and therefore causal conclusions cannot be drawn. For example, it would 


\section{Oliveira et al.}

be important to ask the participants if they had suffered from any mental disorder prior to the COVID-19 outbreak. Also, future research should use longitudinal designs to better understand if the studied factors have a causal effect on levels of anxiety, stress, and depression. Moreover, our sample is not a representative sample of the athletic population. It would be interesting to replicate this study with a sample of athletes that equated different sports, different nationalities, and different cultures. Finally, the concerns associated with resuming sports practice were previously defined by the authors, so there may be other concerns with a significant emotional impact on athletes that were not addressed.

\section{PRACTICAL CONSTRIBUTIONS}

To sum up, the current study demonstrated that most athletes maintained their training routines and also explored the role of certain different contextual variables related to the period of isolation resulting from the COVID-19 pandemic in relation to anxiety, depression, and stress levels. In this sense, this study can contribute to warn sports community about the impact of different contextual variables-related to critical moments in the current or in future pandemics. Also, this study may be understood as a first step into studying the impact of the COVID-19 pandemic in athletes' mental health, since it explored some athleterelated concerns to resumption of sports practice and showed their association to higher levels of anxiety, depression, and stress. The COVID-19 pandemic is a challenging time for all, but some populations, such as athletes, have very specific needs (Hull et al., 2020). The challenges and concerns of athletes may have an impact on returning to the sporting context. In this maelstrom of changes, it is important to identify some of the unique challenges this population may face to ensure these needs are addressed, and therefore protect the health and wellbeing of this population.

\section{REFERENCES}

1. Belvederi-Murri, M., Ekkekakis, P., Magagnoli, M., Zampogna, D., Cattedra, S., Capobianco, L., Serafini, G., Calcagno, P., Zanetidou, S., \& Amore, M. (2019). Physical Exercise in Major Depression: Reducing the Mortality Gap While Improving Clinical Outcomes. Frontiers in $\begin{array}{lll}\text { psychiatry, } & 9, & 762 .\end{array}$

https://doi.org/10.3389/fpsyt.2018.00762

2. Centers for Disease Control and Prevention. (2020, July). Coping with stress. https://www.cdc.gov/coronavirus/2019ncov/daily-life-coping/managing-stressanxiety.html

3. Cohen, J., Cohen, P., West, S., \& Aiken, L. (2003). Applied multiple regression/correlation analysis for the behavioral sciences (3rd ed.). New Jersey, NJ: Lawrence Erlbaum Associates

4. Cohen, S., Kamarck, T., \& Mermelstein, R. (1983). A global measure of perceived stress. Journal of Health and Social Behavior, 24, 386396.

5. Cureton, T. K. (1956). Relationship of physical fitness to athletic performance and sports. Journal of the American Medical Association, 162(12), 1139-1149.

https://doi.org/10.1001/jama.1956.029702900350 10

6. European Platform for Sport Innovation. (2020). Position paper on the impact of the covid-19 crisis on the sport sector. https://epsi.eu/news/positionpaper-on-the-impact-of-the-covid-19-crisis-onthe-sport-sector/

7. FIFPRO. (2020, April). Coronavirus shutdown: Sharp rise in players reporting depression symptoms.

https://www.fifpro.org/en/health/coronaviruscovid-19-page/coronavirus-shutdown-sharp-risein-players-reporting-depression-symptoms

8. Hamouche, S. (2020). COVID-19 and employees' mental health: stressors, moderators and agenda for organizational actions. Emerald Open Research, 2 (15). https://doi.org/10.35241/emeraldopenres.13550.1

9. Hull, J., Loosemore, M., \& Schwellnus, M. (2020). Respiratory health in athletes: facing the COVID-19 challenge. The Lancet Respiratory Medicine, $8 . \quad \mathrm{https} / / / \mathrm{doi}$. org/10.1016/S22132600(20)30175-2

10. Kroenke, K., Spitzer, R. L., Williams, J. B. W., \& Löwe, B. (2009). An ultra-brief screening scale for anxiety and depression: the PHQ-4. Psychosomatics, 50, 613-621.

11. Liew, G.C., Kuan, G., Chin, N.S., \& Hashim, H. A. (2019). Mental toughness in sport. German 


\section{Challenges and emotional impact on Portuguese athletes during COVID-19 pandemic}

Journal of Exercise and Sport Research, 49, 381394. https://doi.org/10.1007/s12662-019-00603-3

12. Mehrsafar, A. H., Gazerani, P., Moghadam Zadeh, A., \& Jaenes Sánchez, J. C. (2020). Addressing potential impact of COVID-19 pandemic on physical and mental health of elite athletes. Brain, behavior, and immunity, 87, 147-148. https://doi.org/10.1016/j.bbi.2020.05.011

13. Oliveira, S., Cunha, M., Rosado, A., \& Ferreira, C. (2021a). Compassionate Coach and Psychological Quality of Life in Portuguese Athletes: Effect of Mediating Variables. Journal of Clinical Sport Psychology. https://doi.org/10.1123/jesp.2020-0058

14. Oliveira, S., Rosado, A., Cunha, M., \& Ferreira, C. (2021b). The compassionate coach scale as perceived by the athlete: development and initial validation in Portuguese athletes. International Journal of Sport and Exercise Psychology. https://doi.org/10.1080/1612197X.2021.1907763

15. Order of Portuguese Psychologists. (May, 2020). Recommendations for Psychologists, athletes and coaches - COVID-19 Pandemic. https://www.ordemdospsicologos.pt/ficheiros/do cumentos/desporto_psicologos_atletas_treinadore s.pdf

16. Psychology \& Performance Practice Group. (2020, April). Mental Health and Performance: Recommendations for Athletes in COVID-19 Pandemic https://www.fnkp.pt/wpcontent/uploads/2020/05/Vs.Rev_Pandemia-

COVID-19-Recomendac $\% \mathrm{CC} \% \overline{\mathrm{A}} 7 \mathrm{o} \% \mathrm{CC} \% 83$ esAtletas.pdf

17. Reardon, C. L., Hainline, B., Aron, C. M., Baron, D., Baum, A. L., Bindra, A., \& Currie, A. (2019). Mental health in elite athletes: International Olympic Committee consensus statement. British Journal of Sports Medicine, 53(11), 667-699. https://doi.org/10.1136/bjsports-2019-100715

18. Schinke, R., Papaioannou, A., Henriksen, K., Si, G., Zhang, L., \& Haberl, P. (2020). Sport psychology services to high performance athletes during COVID-19. International Journal of Sport and Exercise Psychology, 18(3), 269-272. https://doi.org/10.1080/1612197X.2020.1754616

19. Shi, Y., Wang, Y., Shao, C., et al. (2020). COVID19 infection: the perspectives on immune responses. Cell Death \& Differentiation, 27, 14511454. https://doi.org/10.1038/s41418-020-0530-3
20. Toresdahl, B. G., \& Asif, I. M. (2020). Coronavirus Disease 2019 (COVID-19): Considerations for the Competitive Athlete. Sports health, 12(3), 221-224. https://doi.org/10.1177/1941738120918876

21. Trigo, M., Canudo, N., Branco, F., \& Silva, D. (2010). Estudo das propriedades psicométricas da Perceived Stress Scale (PSS) na população portuguesa. Psychologica, 53, 353-378. https://doi.org/10.14195/1647-8606_53_17

22. United Nations. (2020, May). The impact of COVID-19 on sport, physical activity and wellbeing and its effects on social development. https://www.un.org/development/desa/dspd/2020 /05/covid-19-sport/

23. World Health Organization. (2020a, March). WHO Director-General's opening remarks at the media briefing on COVID-19 - 11 March 2020. https://www.who.int/dg/speeches/detail/whodirector-general-s-opening-remarks-at-the-mediabriefing-on-covid-19---11-march-2020

24. World Health Organization. (2020b, February). Updated WHO recommendations for international traffic in relation to COVID-19 outbreak. https://www.who.int/news-room/articlesdetail/updated-who-recommendations-forinternational-traffic-in-relation-to-covid-19outbreak

25. World Health Organization. (2020c, April). Considerations for sports federations/sports event organizers when planning mass gatherings in the context of COVID-19: Interim Guidance. https://apps.who.int/iris/bitstream/handle/10665/ 331764/WHO-2019-nCoV-

Mass_Gatherings_Sports-2020.1-eng.pdf

26. World Health Organization. (2020d, March). Mental health and psychological resilience during the COVID-19 pandemic. https://www.euro.who.int/en/healthtopics/health-emergencies/coronavirus-covid19/news/news/2020/3/mental-health-andpsychological-resilience-during-the-covid-19pandemic

27. World Health Organization. (2020e, March). Physical Activity and Adults: Recommended levels of physical activity for adults aged $18-64$ years.

https://www.who.int/dietphysicalactivity/factshee t_adults/en/. 
Oliveira et al.

28. Wu, Z., \& McGoogan, J. M. (2020). Characteristics of and Important Lessons From the Coronavirus Disease 2019 (COVID-19) Outbreak in China: Summary of a Report of 72314 Cases From the Chinese Center for Disease Control and Prevention. JAMA, 323(13), 1239-1242. https://doi.org/10.1001/jama.2020.2648

29. Belvederi-Murri, M., Ekkekakis, P., Magagnoli, M., Zampogna, D., Cattedra, S., Capobianco, L., Serafini, G., Calcagno, P., Zanetidou, S., \& Amore, M. (2019). Physical Exercise in Major Depression: Reducing the Mortality Gap While Improving Clinical Outcomes. Frontiers in $\begin{array}{lll}\text { psychiatry, } & 9, & 762 .\end{array}$ https://doi.org/10.3389/fpsyt.2018.00762 